\title{
Roadmap to Neutrality - What Foundational Questions Need Answering to Determine One's Ideal Decarbonisation Strategy
}

\author{
Stefan M. Buettner ${ }^{1, *}$ \\ 1 EEP - Institute for Energy Efficiency in Production, University of Stuttgart, 70569 Stuttgart, Germany \\ * Correspondence: Stefan.Buettner@eep.uni-stuttgart.de; Tel.: +49 711 970-1156
}

\begin{abstract}
Considering increasingly ambitious pledges by countries, pressure from society, investors, and clients further up the supply chain, the question for companies is not so much whether to take decarbonisation action, but what action and by when. However, determining an ideal mix of measures to apply 'decarbonisation efficiency' requires more than knowledge of technically feasible measures and how to combine them to achieve the most economic outcome: In this paper, the author describes seven aspects which heavily influence the composition of an 'ideal mix' that executive leadership needs to take a (strategic) position on. These aspects consider underlying motivations and span across (socio-)economic, technical, regulatory, strategic, corporate culture and environmental factors and further underline the necessity of clarity of definitions. How these decisions influence the determination of the decarbonisation-efficient ideal mix of measures, both in principle but also in terms of specific impact is further explored by providing examples. What choices are taken by German manufacturers in several of the aspects is disclosed by insights from about 850 responses to the 'Energy Efficiency Index of German Industry'. Knowledge of the status quo, and clarity in definitions, objectives, time frames and scope are key.
\end{abstract}

Keywords: decarbonisation; climate neutrality; industrial energy saving; strategic decision making; net-zero; roadmapping; energy efficiency; ideal mix; energy efficiency index

\section{Introduction}

\subsection{Background}

Ahead of the United Nations' Climate Conference COP26 in Glasgow, a vast array of severe weather incidences across the globe - floods, storms, droughts, increase in temperature, melting ice-shelves etc. [1] - along with warnings of various bodies [2-5] have presented a thorough argument for policy makers to take into consideration that significant action is required to maintain the ability to limit global warming to well below $2{ }^{\circ} \mathrm{C}$, ideally $1.5^{\circ} \mathrm{C}$ above pre-industrial levels as agreed in the Paris Climate Agreement [6].

The Intergovernmental Panel on Climate Change (IPCC), the International Energy Agency (IEA), the German Energy Agency and many other bodies have published reports, roadmaps, and scenarios $[4,7,8]$ on what needs to be done to meet the target set. The pace of the change in environment suggests actions are better taken sooner rather than later to maintain the ability to meet the target, as well as to keep the required action trajectory manageable.

An increasing number of countries have reacted and, in line with the requirement to submit updated intended nationally determined contributions (INDCs) to the United Nations Framework Convention on Climate Change ahead of COP 26, declared the ambition for net-zero emissions. According to the Climate Action Tracker [9], "over 140 countries had announced or are considering net-zero targets, covering $90 \%$ of global emissions". Net-zero means that emissions remaining after reduction efforts are balanced with offsets (i.e., via carbon sinks or compensatory projects) [10]. While many countries pledge to reach net-zero emissions by 2050, some aim at reaching this goal earlier (e.g., Germany 2045), some later (e.g., China 2060), some at becoming carbon neutral, others at becoming 
climate neutral [11]. Carbon neutral only refers to carbon-dioxide emissions $\left(\mathrm{CO}_{2}\right)$ while climate neutral includes other emissions such as methane etc. How countries aim to achieve these goals, however, remains vastly vague.

As setting a target never automatically leads to it being met with no further action, it is crucial to equip policymakers with the insights needed on how to achieve net-zero effectively. Looking at the calls on governments to act to make sure fighting climate change is given priority may give the impression that it is up to the governments alone to mitigate climate change. By direct action, however, governments only account for the emissions of their immediate actions and on their premises. Subsequently, they have indirect influence on the emissions of their economy through regulatory measures, such as bans, minimum requirements, mandatory action, provision of infrastructure, incentives, and subsidies, in summary the policies they apply.

Typically, the bulk of emissions arise during energy generation and from key economic sectors, such as transport, industry, housing, and agriculture [12-13]. Therefore, achieving climate change targets essentially comes down to getting these sectors to reduce their emissions, usually with aforementioned set of policy measures.

The challenge, however, is to identify what set of measures is effective and economic to decarbonise which part of the economy with. Instructive measures have proven impactful in the past (i.e., minimum standards, phasing-out of incandescent light bulbs, etc.) [14-15], however, noting that achieving net-zero requires emissions to be cut or removed across the board, it is necessary to get as broad individual and intrinsic action as possible. Hence, it is essential to find effective means to trigger an intrinsic wish in stakeholders to reduce emissions, in other words getting their 'buy-in'. This way, rather than avoiding regulations and trying to find loopholes, stakeholders proactively look for means with which they can succeed in meeting targets set by themselves.

Two key challenges arise, (1) to identify means that promise to successfully trigger the (intrinsic) decision to decarbonise, and (2) to provide those who have taken this decision or are at least contemplating to with the means to decarbonise effectively.

Being aware of their own operations in principle, there is good chance for stakeholders to be able to find ways to reduce their emission footprint. The cumulative proactive efforts of stakeholders allow governments to shift attention from spot policing compliance with instructed policies to ensuring the environment needed by stakeholders to be able to decarbonise is in place (i.e. planning capacities, generation and transmission infrastructure, support mechanisms) and to focus on how potential gaps in stakeholder ambitions to meet the countries' goals can be addressed.

\subsection{Industrial Sector of High Relevance for Achieving Net-Zero - But How to Get Started?}

One of the most relevant stakeholders is the industrial sector. Not only does it account for a large proportion of most countries' energy consumption, but also for associated energy- and process related emissions [16-20]. Furthermore, it is in this sector, where shape, performance, durability, energy and resource consumption during production and service life, but also repairability, recyclability, as well as sourcing of the raw materials needed to manufacture products and machinery of all other sectors are determined - be it power stations, turbines, transmission infrastructure equipment, vehicles, building parts, machinery, consumer electronics, clothing, or furniture.

Therefore, decarbonisation in manufacturing can be considered as a critical enabler to the question of how to achieve carbon or climate neutrality. A growing number of studies thus explore pathways for deep decarbonisation, particularly energy intensive industries. According to Nurdiawati et al. [21] (p. 2) many of these studies "focused much on the technological pathways and less on the supportive enabling reforms that would facilitate their uptake". Bauer et al. [22] are exploring pathways for decarbonising four emission intensive sectors even moving beyond direct emissions, also considering value-chain and end-consumers emissions. Bataille et al. [23] (p. 1) present an "integrated [policy] strategy for a managed transition" in energy intensive industries, also including technology options, and Rissman et al. [24] review policy options, sociological and technological 
and practical solutions in detail. These studies address decarbonisation of industry from either a policy, a supply side or technology perspective - often with a focus on energy intensive industries - but are short of giving corporate stakeholders (irrespective of their company's energy intensity) concrete advice on how to get started from an individual company's perspective. Similarly, studies like the one of Johnson et al. [25] analyse and compare national roadmaps for decarbonising heavy industry on a global scale alongside factors such as ambition, financial effort and mitigation measures, thus again leaving a gap when it comes to company-tailored advice.

Consultancies and advisories fill this gap insufficiently. While they indicate what steps have to be undertaken by a stakeholder to shape a decarbonisation roadmap from a company perspective in general [26-28], they either do not go into sufficient detail, or do not address the prerequisite, qualifying steps, notably those of strategic decision making. These, such as the motivation leading to the decision to decarbonise, however often have serious implications on the shape of an 'ideal' decarbonisation strategy and how it can be implemented effectively.

\subsection{The Issue: Enabling Corporate Stakeholders to Decarbonise Effectively}

The present article addresses this gap by illustrating what seven foundational questions matter and need answering to provide practical guidance on how to shape an effective and tailored decarbonisation strategy. Derived from professional practice and applying a mix-methods approach building on data gathered via the Energy Efficiency Index of German Industry (EEI) [29], the work addresses underlying motivations and spans across (socio-)economic, technical, regulatory, strategic, corporate culture and environmental factors and further underlines the necessity of a mutual understanding, clarity and communication of definitions and targets.

Plenty of companies have made emission reduction related pledges already. However, these constitute only a small share of global manufacturing companies, even though being big in size individually. To achieve net-zero on a societal level, however, it is not sufficient to address the largest emitters only, but to find ways to reach at best all emitters and get their 'buy-in' irrespective of their emission intensity or size.

Tackling these challenges, this work aims at aiding executive leadership, as well as other functions within companies relevant to the transition, in shaping their pathway to net-zero effectively. It further provides insights to policy makers, service providers, financiers, and the general public on often not obvious obstacles, needs for support, and infrastructure as well as interdependencies along the process. Several of the general principles may also apply and therefore prove to be helpful to other sectors, state actors or individuals.

The article was inspired by a company invested in advancing in energy efficiency, but not yet seeing the point in decarbonisation. Following the explanation on why, due to a series of external pressure points, it is of the best interest to take decarbonisation seriously, the manager expressed that immediate action appears necessary and enquired, to brief the company's CEO, what aspects the executive leadership of a manufacturer needs to take into consideration to shape an effective and economic strategy.

While the analysis may largely apply to companies and other sectors in general, the author focuses on (predominantly manufacturing) companies that have taken the decision to decarbonise or contemplate whether to do so.

This article provides an overview of seven foundational questions and why these matter to enable a general understanding, as well as to provide practical guidance on how to shape an effective and tailored decarbonisation strategy. Results show, that clarity in definitions, objectives, time frames and scope, as well as a thorough understanding of the status quo and technically feasible options are key, however with changing emission and energy prices, digital solutions and an adjusted approach to economic viability calculation are needed to help keeping such strategy ideal.

\section{Materials and Methods}


In an iterative process, starting in May 2019, the author analysed manufacturing companies' stand towards decarbonisation with a particular focus on local decarbonisation efforts, notably around energy efficiency.

The qualitative element of the analysis of companies' actions, ambitions and intentions is based on direct conversations with companies, related business press, newspaper articles, press releases and pledges, both from a company, and an overall perspective, as well as from feedback received in context of public speeches held at events concerning decarbonising industry.

Observations from this procedure which promised to shed light on aspects concerning willingness to decarbonise, and actual progress of decarbonisation in companies were then tested quantitatively within the framework of the Energy Efficiency Index of German Industry (EEI) to confirm the anecdotal evidence.

Introduced in 2013, EEI surveys German manufacturing companies of all sizes, energy intensities and across 27 sub-sectors twice a year. It aims at gaining an understanding of companies' stands, expectations, plans, opinions, experiences towards energy efficiency and increasingly also decarbonisation. EEI data is gathered applying a mixedmethods approach combining online (ca. $10 \%$ ) and telephone surveys (ca. $90 \%$ ) [29].

An iterative process was applied to deepen the understanding of what interdependencies, which elements are the foundational ingredients that enable - or hold back - decarbonisation. Whenever EEI uncovered a relevant finding, the next data collection, after pre-testing, was utilised to drill deeper. In total, evidence from five data collections is considered in context of this article (cf. Table 1).

Table 1. Energy Efficiency Index of German Industry (EEI) datasets referred to [30-34].

\begin{tabular}{lll}
\hline EEI Data Collection & Data collection period & Observations \\
\hline $2019 / 2$ & 2019 Oct - Nov & 915 \\
$2020 / 1$ & 2020 May & 863 \\
$2020 / 2$ & 2020 Oct - Nov & 884 \\
$2021 / 1$ & 2021 April - May & 717 \\
$2021 / 2$ & 2021 Nov - 2022 Jan & 865 \\
\hline
\end{tabular}

To provide a general overview, a series of EEI questions of the past five data collections were identified to illustrate selected aspects. They span across (a) whether companies plan to decarbonise, and (b) if so, by when. What level of ambition they have for (c) 2025 and (d) for 2030 and (e) optimising for what dimension(s). Based on (f) what motivation they do so, and (g) what weight different determinants have in deciding for decarbonisation measures. Beside the area of observation (h), EEI explores the increasing relevance of product carbon footprints (i). The awareness of company's emission footprint (j), along with knowledge about energy consumption and type $(k, 1)$, and energy saving potentials $(\mathrm{m})$ are explored to assess company's knowledge of their status quo [30-34].

\section{Results}

Before taking a decision, one often considers the implications and repercussions of that decision beforehand. However, even after a thorough consideration it is not unlikely that an aspect that impacts significantly on the overall ambition is overlooked - unless one has succeeded in a very similar or identical undertaking before. Decarbonising one's business, is to some extent like building a house for the first time. After completion, one has learnt a lot on what to do better or differently the next time. However, in many instances one only builds one house (if any). Roughly the same is the case with decarbonisation: once it is done - however (in-)efficiently - there is rarely a situation where one does it again from scratch (unless one has multiple sites and started with a pilot one or offers the experience as a service to others). Again, similar to one's home, there remains the prospect 
of continuous optimisation: some of it might be improved incrementally, some other interventions would require significant interference if at all possible (for example converting from a radiator-based heating system to fitting underfloor heating to allow the installed heat pump to serve the home with heat more efficiently [35].

Therefore, it is of high relevance - to stakeholders of any sector - to find answers to seven foundational questions, ideally before, but at least simultaneously to taking action. It is the response to these that only allow to determine one's ideal decarbonisation strategy or, whether to take the decision to go ahead and act, respectively openly pledge to take action.

(1) Terminology

(2) Optimisation variable

(3) Level of ambition

(4) Area of observation

(5) Motivation and needs

(6) Priorities

(7) Status quo

Based on the responses to these, it is then possible to derive (a) general, and (b) specific routes of action to determine a decarbonisation strategy suiting one's situation, goals, and opportunities. Making use of (c) digitalisation and (d) an adjusted form of economic viability calculations allows to find one's ideal roadmap to neutrality.

Why these seven, one could argue. Essentially, every one of them is guided by the notion of what could go wrong (or has gone wrong elsewhere), respectively harm efficiency and/or effectiveness of achieving the goal set and how this can be avoided.

As put by Rissmann et al., "the best practice in designing efficient industrial operations is to analyse the entire process by working "backwards" from the desired application to the energy consuming-equipment" [24] (p. 16). Transposed to the context of this article, the "desired application" reflects the desired outcome.

In this context, however the outcome needs to be further specified as decarbonisation can be understood differently, achieved differently, and should be pursued differently if it is to address different motivations or to consider different priorities. Therefore, similar to Rissman et al. referring to increasing efficiency of industrial systems and processes, "design should be an integrative process that accounts for how each part of the system affects other parts." [24] (p. 16)

In this article, "design" refers to the preliminary steps (i.e., strategic considerations) that need to be taken, typically by executive leadership, to allow them, and subsequently their company to shape and pursue an effective and efficient roadmap to neutrality.

Other than the practical "design layers" that describe step by step the "how" of increasing efficiency, [24] (p. 16) [36], the seven foundational questions address the "what", "where", "by when" and "why", as well as the "how", however, on a more strategic than a specifically practical level.

To validate their relevance, they have also been tested by EEI, in direct interaction with companies, practitioners, policy stakeholders, indirectly in context of feedback to speeches and observing policy, as well as corporate practice.

\subsection{Terminology}

The foundation of an effective decarbonisation strategy, as of any other work in any other area, is to establish mutual understanding and clarity across all stakeholders involved regarding the terms used and how they are understood. Otherwise, misunderstanding or misperception will lead to either unnecessary action being taken or, worse, essential action being overlooked.

Buettner [37] points out that a key reason for carbon- and climate neutrality being frequently mixed-up is that while $\mathrm{CO}_{2}$-equivalents $\left(\mathrm{CO}_{2}\right.$-eq. $)$ are the 'currency' to measure 
greenhouse gas (GHG) emissions adversely affecting our climate, the suffix "-eq", standing for equivalents, gets easily lost on the way, notably in oral or simplified conversation and correspondence.

That aside, it is further possible that, fortunately decreasingly so over the past three years, the difference between carbon neutrality, climate neutrality and environmental neutrality itself is not clear. In short, climate neutrality exceeds the ambition of carbon neutrality by also addressing Methane and all other gases that have a warming potential for the atmosphere (GHGs), such as nitrous oxide and hydrofluorocarbons. Environmental neutrality reaches even further and addresses all other gases and substances that have a negative impact on the environment (such as particulate matter and sulphur dioxide, cf. Figure 1) [37].
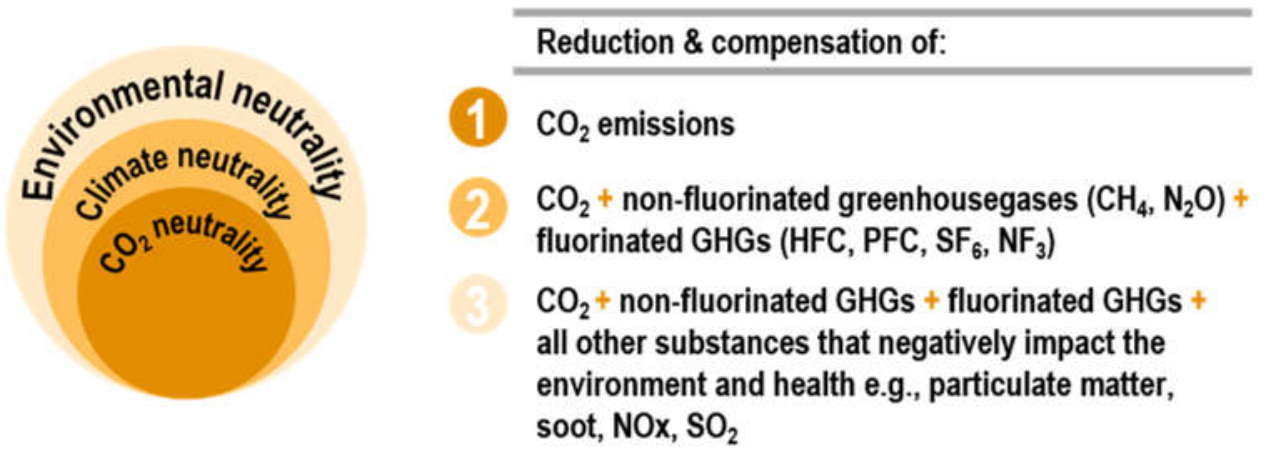

Illustration based on UNECE GEEE-7/2020/INF.2

Figure 1. Defining different neutralities and what is needed to achieve them (Buettner and Wang, 2022) [37-38].

This often still lacking clarity regarding definitions can also be observed beyond private sector stakeholders, in the public sector, in politics, public discussion and in media, for instance when reporting on targets: The German business paper Handelsblatt and the New York times diverge over the target set by Japan in late 2020. According to Handelsblatt [39], Japan strives to climate neutrality, while the New York Times [40] reports carbon neutrality to be the target. Without the means to retrieve the information from the original source in the language of origin, one will not know which neutrality is being targeted by Japan.

Therefore, establishing clarity of the target dimension and how it is being defined is key [37]; this relates to all stakeholders involved in the process (i.e., within a company) and thus is first success criterion to any kind of net-zero pledge.

\subsection{Optimisation variable}

A strategy can only be effective if it serves achieving a clearly defined objective, in this instance one or multiple target dimensions that serve as variable(s) that are optimised for [41]. In context of emission reduction optimisation, common variables are (not exhaustive):

a) Reduction of energy consumption (reduces emissions)

b) $\mathrm{CO}_{2}$-neutrality (usually includes reduction of a)

c) Climate neutrality (includes $\mathbf{a}$ and $\mathbf{b}$ and is policy goal of e.g., EU and Germany)

d) Environmental neutrality (includes $\mathbf{a}, \mathbf{b}$ and $\mathbf{c}$ )

For stakeholders in general, but also for a company in particular, it makes sense to pursue pragmatic pathways to effectively achieve what is needed; it however is also relevant to observe the legislator's target setting, notably its target dimension. If climate neutrality is the country's target, policies are very likely tailored to serve this goal and companies are well advised to take this into consideration rather than only looking at a subset of this dimension (e.g., carbon neutrality). 
Even though the optimisation variables a-d are not mutually exclusive, the Energy Efficiency Index of German Industry (EEI) observed in its second data collection 2020 [32], that the 834 participating manufacturers on average optimise their companies towards two target dimensions. This suggests, that within a further reaching optimisation variable, they also aim at optimising for (at least) one of its components in particular: Most companies $(58 \%)$ optimise towards a reduction of energy demand, second most (53\%) for the reduction of $\mathrm{CO}_{2}$-emissions. The fact that just over a third of companies indicate to optimise for GHG reductions (36\%) or overall environmental impacts (36\%) leads to the assumption that GHG reductions or, in other words ingredients to reach climate neutrality, remain abstract, and what it means in the industrial context a sort of 'black box'. This even though climate neutrality has been known to be the target dimension of both Germany and the European Union at the time of the data collection (cf. Figure 2) [32].
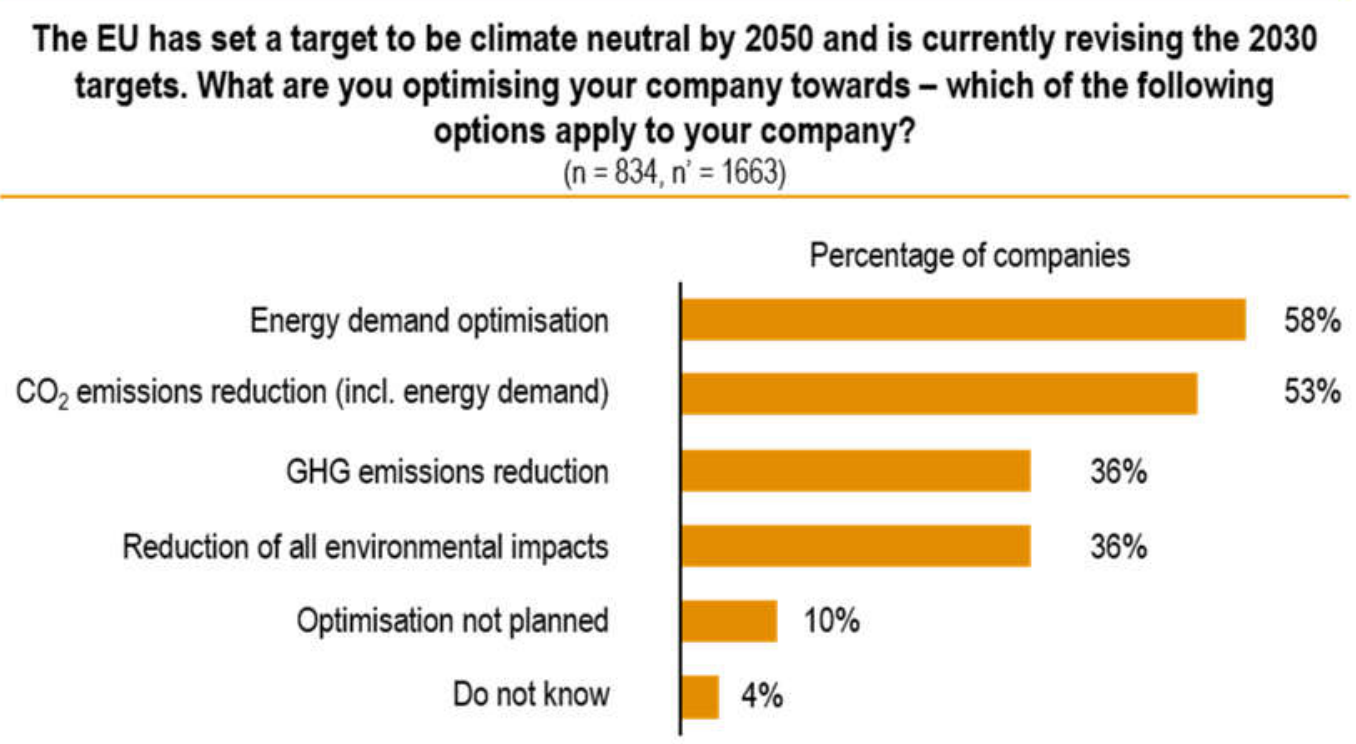

Figure 2. Target dimensions companies optimise towards [32]

Addressing the potential issue of climate neutrality being rather complex due to some of its hard to identify and quantify sub-components (e.g., nitrous oxide and hydrofluorocarbon.), the United Nations Economic Commission for Europe's Task Force on Carbon Neutrality are pursuing an in-between target dimension: Carbon neutrality plus methane reduction (and hydrogen) in its carbon neutrality project [42] (para 17) [43]. An agreement to reduce global methane emissions in context of COP26, counting more than 100 countries to-date [44], indicates the notion of 'carbon neutrality + ' to be tangible for those that find it difficult to commit to the further reaching climate neutrality goal.

Being mutually aware of terminologies, determining those optimisation variable(s) as target dimension and overarching goal that stakeholders are aiming to work and orient their forthcoming actions towards are thus the second success criterion on the path to netzero.

\subsection{Level of ambition}

The choice of target dimension (e.g., carbon or climate neutrality) only provides a limited indication of the level of ambition as it remains unclear by when it is to be achieved. Very timely target years thus usually suggest a high level of ambition, whereas far into the future targets indicate either a very cautious regime, limited means to reach the goal earlier or simply lacking ambition. The German energy provider RWE plans to become climate neutral two years after the scheduled German coal phase-out - in 2040 
[45]. Very timely target years, however often significantly depend upon compensatory measures rather than actual emission reductions [46].

Clarity on the level of ambition is only achieved when it is also determined upon (a) by when the goal should be achieved and (b) what percentage reduction of the target dimension this is set to be. This is of high relevance as there are scenarios in which a $100 \%$ reduction either cannot be achieved or simply is not the goal. This is for instance if the target dimension is energy consumption, or if proportions of the energy or process related emissions cannot be avoided through reduction, substitution, or other alike means. In such cases, it could be attempted to balance remaining emissions through offsets (e.g., compensation) to manage a 'net-zero' instead of the 'actual zero' state in respect to their target dimension. There are, however, several stakeholders the author works with, that object to compensatory projects by principle and exclude these from their feasible set of decarbonisation measures and thus exclude themselves from the option of reaching 'net'zero.

Further to defining an ambition in respect to the finish line, it makes sense to also consider interim milestones to ensure the target can be met and potentially unpopular interventions are not being postponed to the future. In addition to the aspect of popularity, interim milestones ensure that the trajectory needed to achieve the target is being matched with the actual trajectory and, if necessary, adjustments to it are being launched. While there is no requirement to determine interim goals for companies, it makes sense to do so in terms of year and level of achievement by then.

Many countries have set milestones for (at least) 2030 [47] (p.41). As thorough assessments by these countries into the state of play are to be expected, it makes sense for stakeholders operating in these countries to define a milestone that ideally is already following the country's target for the respective year(s), too. The case of Germany and the Netherlands being sued at their constitutional courts successfully for undertaking insufficient short- to medium-term action to be able to meet their 2030 targets underline that additional interim milestones, and if necessary, taking additional action, could be of relevance $[48,49]$. This is also why the outcome of the Glasgow Climate Conference COP26 encourages revisiting the current level of action, status and subsequent tightening of pledges in shorter cycles than originally agreed upon in the Paris Climate Agreement (Art. 4 (9)) $[6,50]$.

Countries however can only succeed in meeting their (climate) goals set, if they get the individual emitters, notably across buildings, transport, and industry, to reduce their emissions.

Looking at the ambitions of German manufacturing, $59 \%$ of the 852 companies participating in the EEI in autumn 2019, ahead of the COVID-pandemic, indicated they plan to achieve net-zero. Of these 488 , two thirds aim to have met this goal already before or by 2025 (cf. Figure 3). Peaking numbers in 2025, 2030, 2035, 2040 and 2045 suggest that semi-decades are chosen by many companies as their target years or at least milestones. The data further suggests that a vast majority of companies participating in the EEI prefer taking substantial immediate or at least short-term action [30]. 
Target year net carbon neutrality $(n=488)$

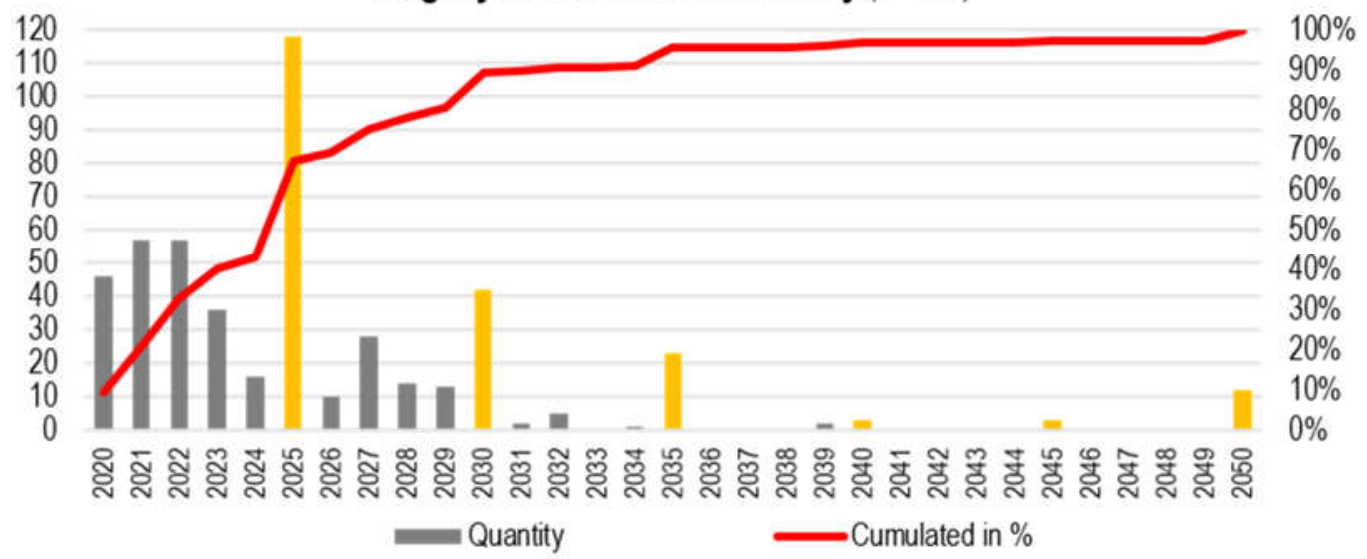

Figure 3. By when do companies plan to reach net carbon neutrality? [29-30]

Taking the likely impact of the COVID-pandemic into consideration and addressing the apparently important milestone year 2025, the first iteration of EEI in 2020 found that the 611 participating companies on average, and based on 2019 figures, aim at reducing their GHG emissions by $22.09 \%$ by then [31]. Asking for their 2030 ambitions at the time when the enhanced target of the European Commission for 2030 was being discussed (autumn 2020), 415 companies participating in the $2^{\text {nd }}$ data collection of EEI in 2020 expressed to aim for a $26.43 \%$ GHG reduction (based on 2019) [32]. This data confirms, that (at least participating) companies consider substantial short-term action, accounting for more than $80 \%$ of what is planned for the whole decade, to happen within its first half. The arising curve of ambition appears to follow a path similar to limited growth functions, whereas policy action is often perceived to follow the opposite path of an exponential growth curve slowly growing towards 2030 and then taking up pace. The action gap arising from this/from what stakeholders need to be able to meet their goals, and the current impact of policy is explored further by Buettner et al. [51].

The level of ambition - the combination of target dimension, \%-goal, and due date can either be 'simply' determined by stakeholders, respectively their executive management, or be set once 'all cards are on deck', meaning all relevant (limiting) factors and potentials, feasible measures, as well as their costs are known. Irrespective of when exactly this definition is taken, setting, and announcing a level of ambition is the third success criterion on the path to net-zero.

\subsection{Area of observation}

In the context of target setting, it is not always clear and obvious what the area of observation, respectively the 'system barrier' is. Like the necessity to establish clarity on definitions, it is necessary to define what the set target dimension and level of ambition refer to.

This leads to three questions that need to be considered by stakeholders.

(1) Does the target apply to one site, multiple sites, all sites of the stakeholder, or only to those in whose countries' some form of $\mathrm{CO}_{2}$-levy is operational or considered, or only sites in selected countries, e.g., Germany? Intuitively, it would be understandable if stakeholders prioritise those sites where there is an elevated levy-induced 'incentive' to take action, respectively those where the enabling environment makes it easier to succeed when taking action. From the author's practical experience, companies often initially focus on one site, or sites within their home country and then, when actions prove to be successful, they gradually expand beyond both geographically and in terms of efforts taken on the initial site.

(2) Are we referring to emissions and energy use in relation to this site/these sites only, and if so, including or excluding the corporate vehicle fleet (Scope 1+2,). Or does the ambition go beyond the direct and indirect emissions that are under quasi-direct control 
of the stakeholder? Such Scope 3 emissions arise indirectly from one's action but are often outwit direct control, include business travel, the workforce's commute and additional emissions arising along up- and downstream supply chains (cf. Figure 4) [52].

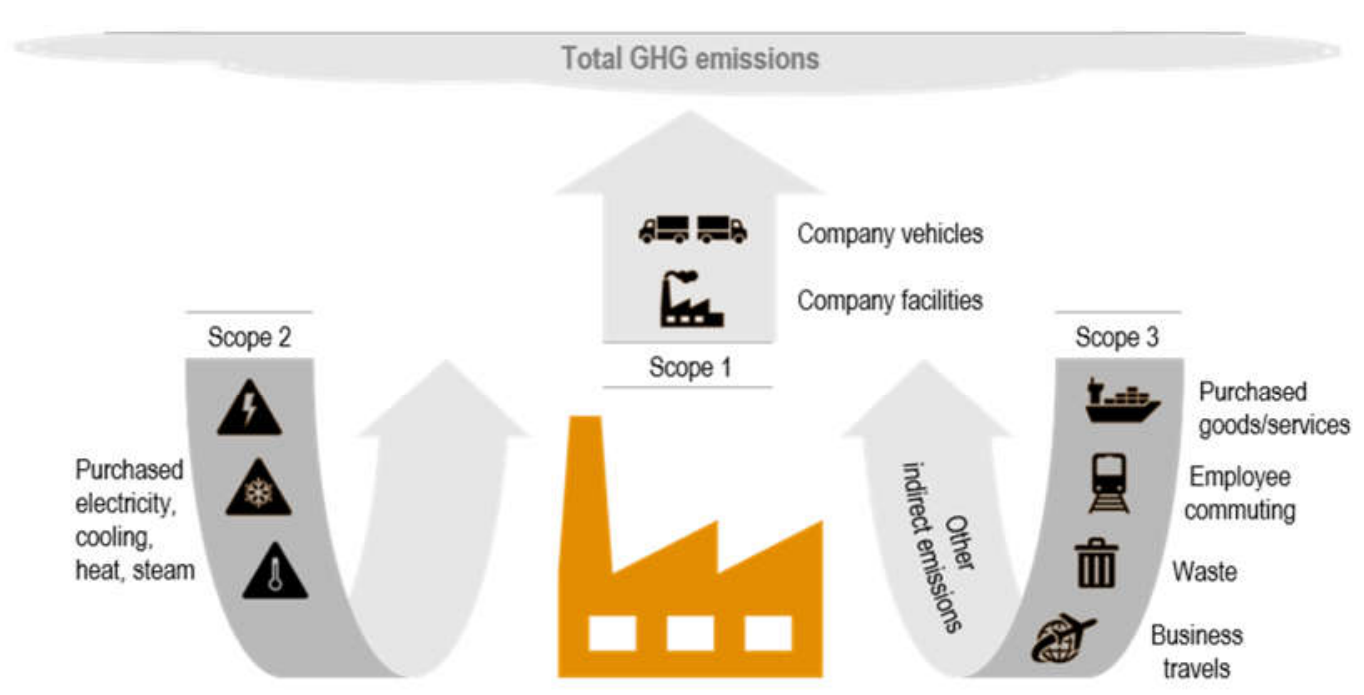

Illustration based on GHG protocol

Figure 4: Carbon footprint assessment Scopes based on the GHG protocol $[38,52]$

To the author's experience, most companies initially address their energy-related emissions (Scope 2), as well as emissions directly arising from their work (Scope 1) due to the complexities of addressing Scope 3 emissions. Complexities arise predominantly out of potential double counting: Scope 1 emissions of one company might be Scope 3 emissions of another company [52-53]. Currently under investigation by EEI in its $2^{\text {nd }}$ data collection 2021, interim analysis suggests that $77 \%$ of the $848(846,843)$ companies responding to this question strive to address Scope 1 emissions or have done so successfully already, $78 \%$ Scope 2 and $75 \%$ Scope 3 emissions. Further analysis of the new data will allow to confirm whether the observation that companies on average only address Scope 3 after a head start on Scope 1 and 2. The interim analysis suggests so: the progress is furthest in respect to Scope 2, followed by Scope 1 and with a substantial gap Scope 3 . Understandable as Scope 2 is 'easiest' to achieve by optimising energy supply contracts [34].

(3) Approaching emissions from a different, a product angle, are only those emissions considered up to the point when (a) a product leaves the premises or arrives at the customer/the shop? Or is the additional emission footprint of the product (b) arising during its useful life, or (c) even until it is fully disassembled \& recycled of relevance, too? Particularly in the automotive industry (b) is of high relevance to meet the European Union's requirement on new vehicles to not exceed $95 \mathrm{~g}$ of $\mathrm{CO}_{2}$-eq per $\mathrm{km}$ on fleet average to avoid being fined 95 Euros per gram and vehicle exceeding the average [54]. Considering the large footprint, the manufacture of Lithium-Ion batteries, but also steel, aluminium etc. carry, manufacturers like Volkswagen work to sell their electric vehicles with a net-zero footprint at the point of handover [55]. A significant undertaking, as many end products, scope 3 emissions make up more than $75^{\circ} \%$ of the overall "Product Carbon Footprint" (PCF), $82 \%$ in the automotive industry [56] (p.9).

Not only in the automotive industry, PCFs are found increasingly often, also BASF announced to assess the carbon footprint of all sales products [57]. Interim analysis of EEIs second data collection in 2021 suggest that $37 \%$ of 829 companies responding to this question consider the PCF until the point of handover, $13 \%$ until the end of useful life and $21 \%$ until the product is fully recycled/disposed of. However, $29 \%$ do not consider their products' PCF to this point. In total, almost $71 \%$ of companies work to offer products with 
a 'net-zero' footprint in one form or another, at least in respect to the point of handover [34].

As the bandwidth and efforts required largely differ depending on what system barriers are being set, defining the area of observation constitutes the fourth success criterion to reach net-zero.

\subsection{Motivation and needs}

Beyond the somewhat technical questions of what, by when and how far, it is of critical relevance to explore why decarbonisation is sought. What is the underlying motivation of the executive leadership / the stakeholder for pursuing net-zero? Motivation plays a large role in determining one's ideal strategy and mix of measures, as elements that are of high internal (e.g., corporate culture) or external (e.g., legislation) relevance may be emphasised over a purely technical composition of measures. The motivation also determines how the topic of decarbonisation is embedded in the stakeholder's overall strategy. Common motivators include (not exhaustive) [58]:

- Requirements of the upstream supply-chain

- Requirements of investors / shareholders

- Image improvement: display leadership and innovativeness

- Image improvement: attracting and retaining skilled personnel

- Pursuing societal responsibility and corporate culture

- Meeting societal expectations

- Demands from policymakers and meeting legal requirements

- Long-term economic advantages, including building up competency

- $\quad$ Reduction risks from external shocks, such as energy price and acquisition and emission costs.

- $\quad$ Ensuring security of supply arising from (micro-) outages.

As Buettner and König [58] outline analysing these motivators, there is an increasing pressure to take action, triggered by both, but not only, investors and up-stream supplychains. The latter has just been confirmed by EEI [34]: around a third of 836 participating companies are facing emission relating contractual demands from their upstream supplychain. Image is not only of relevance to remain able to sell one's products but also to attract and retain scarce skilled personnel. The steeply increasing price of (a) $\mathrm{CO}_{2}$ within the European Emission trading system (EU ETS, currently at $96 \mathrm{EUR} / \mathrm{tCO}$-eq, [59], (b) electricity and (c) gas are an increasing cause of concern among stakeholders [60-63].

As decarbonisation measures that best address the various motivators can differ largely, getting clear on the main motivator(s) of deciding to act constitutes the fifth success criterion on the path to net-zero.

\subsection{Priorities}

While answering the question of why, when and what are essential foundation of determining a roadmap to neutrality, the roadmap can only succeed if further decision criteria are being determined. These criteria are needed to rank and filter feasible measures simultaneously or after scoring how well these measures address the key motivators. Decision criteria include (not exhaustive) [64]:

- Level of investment

- Investment cost per tonne of $\mathrm{CO}_{2}$-eq. avoided

- $\quad$ Emission cost savings (absolute or relative to invest)

- Image effect through visible measures

- Expected increase in productivity

- Technical aspects \& risks (complexity, difficulty level)

- Disruption of operations (cross-cutting-, support processes or core processes)

- Implementation competence (experience with type of measure or access to personnel with necessary skills)

- Impact on company valuation 
- Payback time (including emission-related opportunity costs of inaction)

- Availability of required material and equipment (supply bottlenecks)

Analysing data of the EEI [31], Buettner and König found that economic factors such as absolute and relative level of investment have highest priority as decision criteria [64]. That said, they also found that technical aspects are third most frequently mentioned as primary decision criteria, having asked 787 companies. They further identified that the aggregate findings diverge significantly when assessing the top 3 decision factors from a company size, energy intensity or sub-sectorial perspective. In context of the GHG reduction target set, looking at the primary decision factor only, implementation competence stands out (cf. Figure 5). Either companies setting a particularly ambitious GHG reduction target (understandably) look particularly at their implementation competence when deciding which action(s) to pursue or, companies that have (access to) implementation competence are (able to) setting more ambitious targets. At least these two readings appear to play a role for the upper two quartiles of companies illustrated in Figure 5 indicting 'implementation competence' to be their primary decision criteria for selection of individual measures, as the median GHG reduction target is at the same level as for the other primary decision criteria [31].

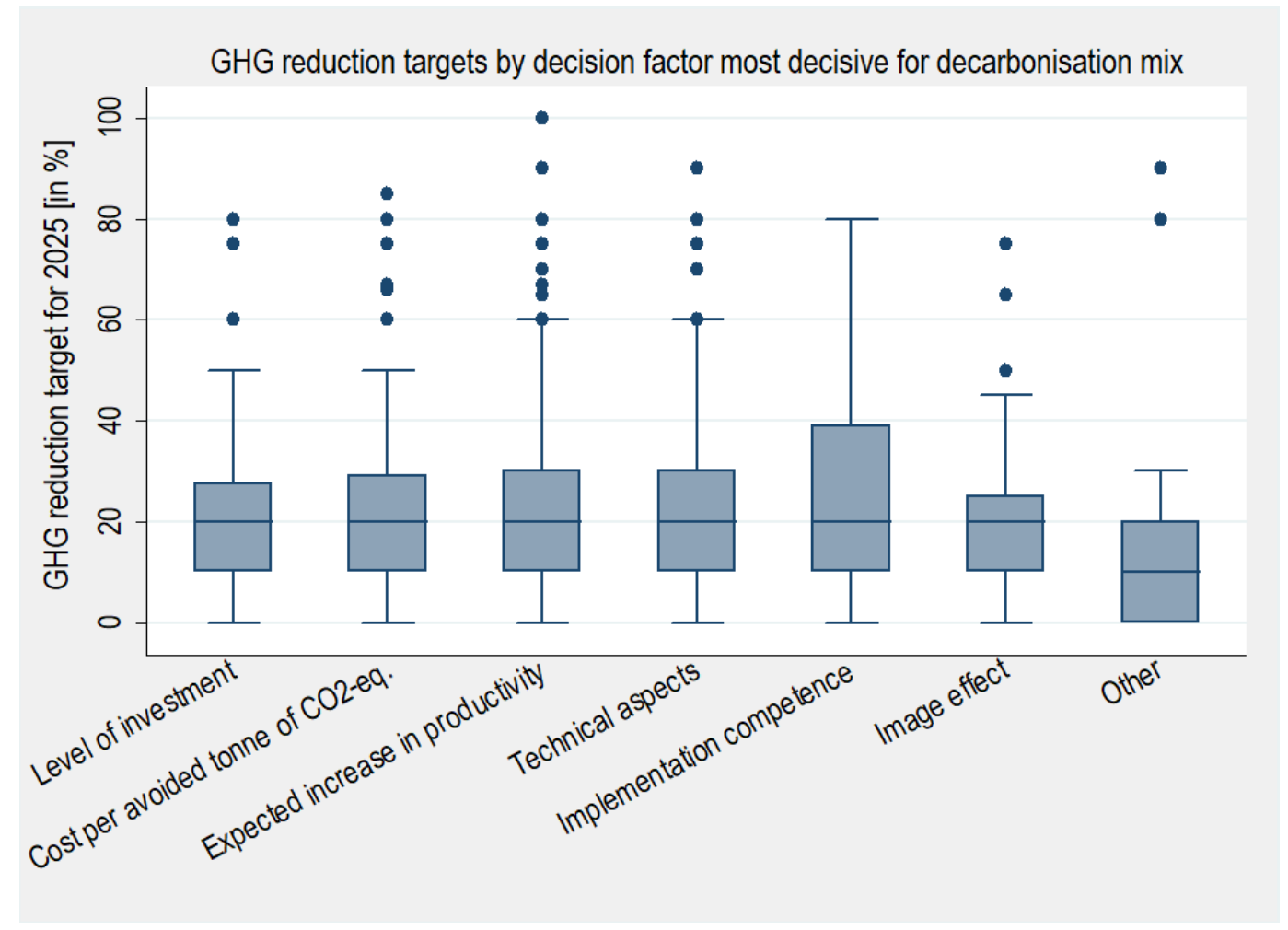

Figure 5: GHG reduction targets by decision factor most decisive for decarbonisation mix [31]

Since the criteria according to which measures are vetted for feasibility and ranked have a significant impact on how the set of individual measures of a decarbonisation roadmap will look like, deciding upon the top three determinants or their ranking order is the sixth success criterion on the way to net-zero.

\subsection{Status Quo}

While the first six success criteria are largely a strategic and economic decision to be taken by the stakeholder, they are not sufficient to derive a successful decarbonisation strategy. Determining one's ideal decarbonisation strategy and subsequently a concrete set of measures is dependent on knowing about where one stands right now, the status quo. As simple determining the status quo sounds, it requires a thorough assessment across various dimensions: 
(a) What has already been done? How is the state of the sites, machinery and equipment? Are there any obvious low hanging fruits?

(b) What intervention is approaching anyway? This can be replacement investments, a restructuring of the production line, process or product range.

(c) How 'safe' is the site in its existence? This is of relevance if investing into high efficiency technologies that are pricey to acquire but promise large relative energy and emission savings. If the (non-environmental) sustainability of the business model or production technology is questionable it might however not make sense to invest large sums at that site.

(d) What is the current energy consumption per type of fuel and site, what are the energy and process-related emissions in respect to the target dimension and area of observation? Based on this information stakeholders will know where they are starting from and potentially also where interventions might promise the biggest impact per effort taken.

(e) What are the local conditions?

- Are there undeveloped areas or available roof space? For instance, for on-site generation of renewable energy, energy storage or heat recovery systems.

- How are the climatic conditions? This includes temperature range (e.g. for air/air heat pumps or air conditioning needs and level of insulation), solar radiation (to harness solar energy), wind and air corridors (to apply micro wind generation or use passive ventilation), adjacent waters (for micro-hydro or air/water heat pumps), geology (regarding earth quake risk and for geothermal energy including air/ground heat pumps) and environmental protection zones (e.g. limited development due to protected species or drinking water protection areas)

- How is the surrounding infrastructure? Access to overland power lines, proximity to wind farms, solar parks or hydro power stations, are there nearby plots of land that would be suitable for these (for off-premises self-generation).

- Who is in the neighbourhood? This is primarily the proximity to entities with whom a symbiotic relationship could be built, typically a sender or recipient of secondary energy or secondary raw materials either on the stakeholders' site (i.e., pre-heating of processes), the industrial estate or borough (i.e., feeding waste heat into district heating grid as Aurubis does for Hamburg's Hafencity) [65]. Here, it also plays a role how ambitious the local authority is, as well as the state, region and country the site is located in and further whether there are support- and co-funding schemes or other support-mechanisms in place to benefit from or to reduce the overall investments.

According to EEI, about half of participating companies have not been aware of their energy- or process related emission footprint at time of participation (cf. Figure 6) [32]. Apart from lighting, the majority of companies were not aware of their percentage energy saving potentials of the cross-cutting technologies they use (cf. Figure 7) [33]. More than four out of ten companies were not aware what proportion of their energy is used for heating and cooling (cf. Figure 8), which is in contrast to electricity rather immobile, harder to electrify but offers great potentials for waste energy utilisation, that $22 \%$ of participating companies do not harness at all (cf. Figure 9) [33]. 


\section{Do you know the $\mathrm{CO}_{2}$-emissions of your company?}

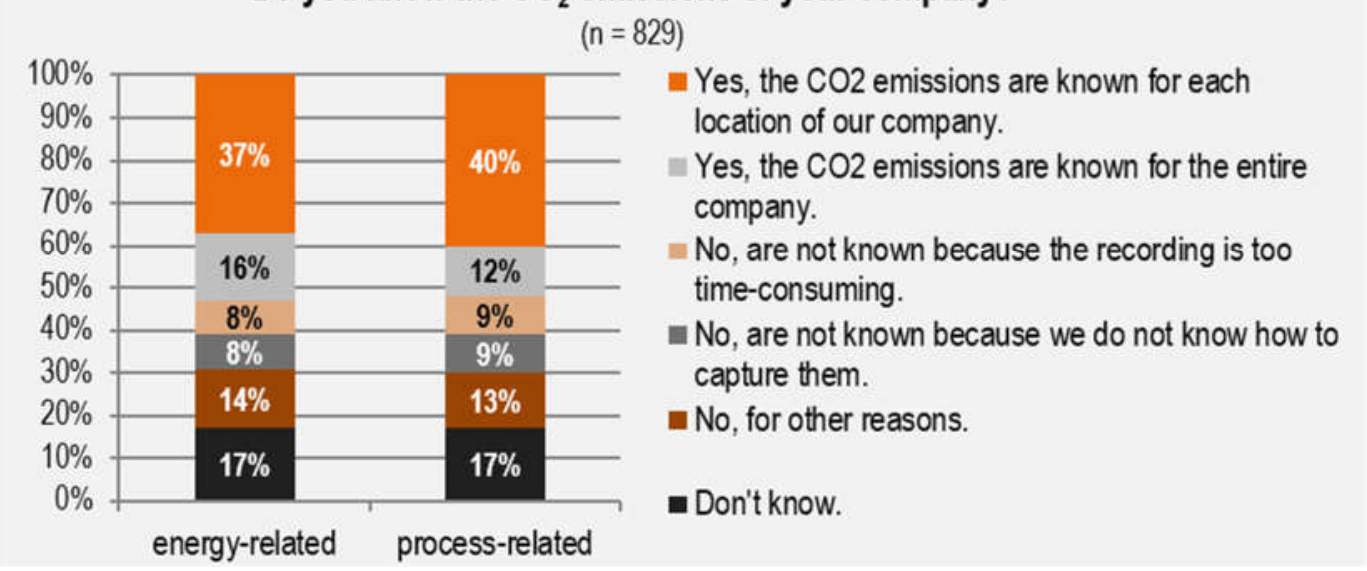

Figure 6: Companies' knowledge of energy- and process-related $\mathrm{CO}_{2}$-emissions [32]

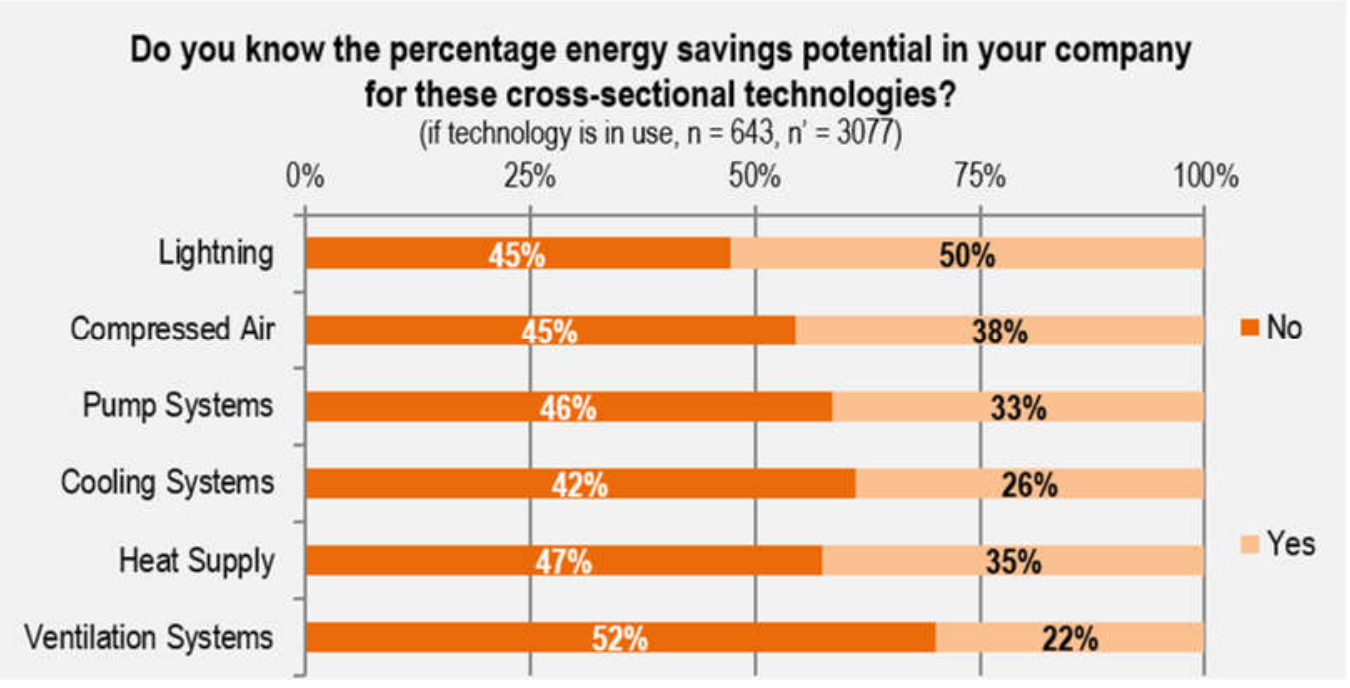

Figure 7: Companies' knowledge of their percentage energy savings potential in cross-cutting technologies they use [33]

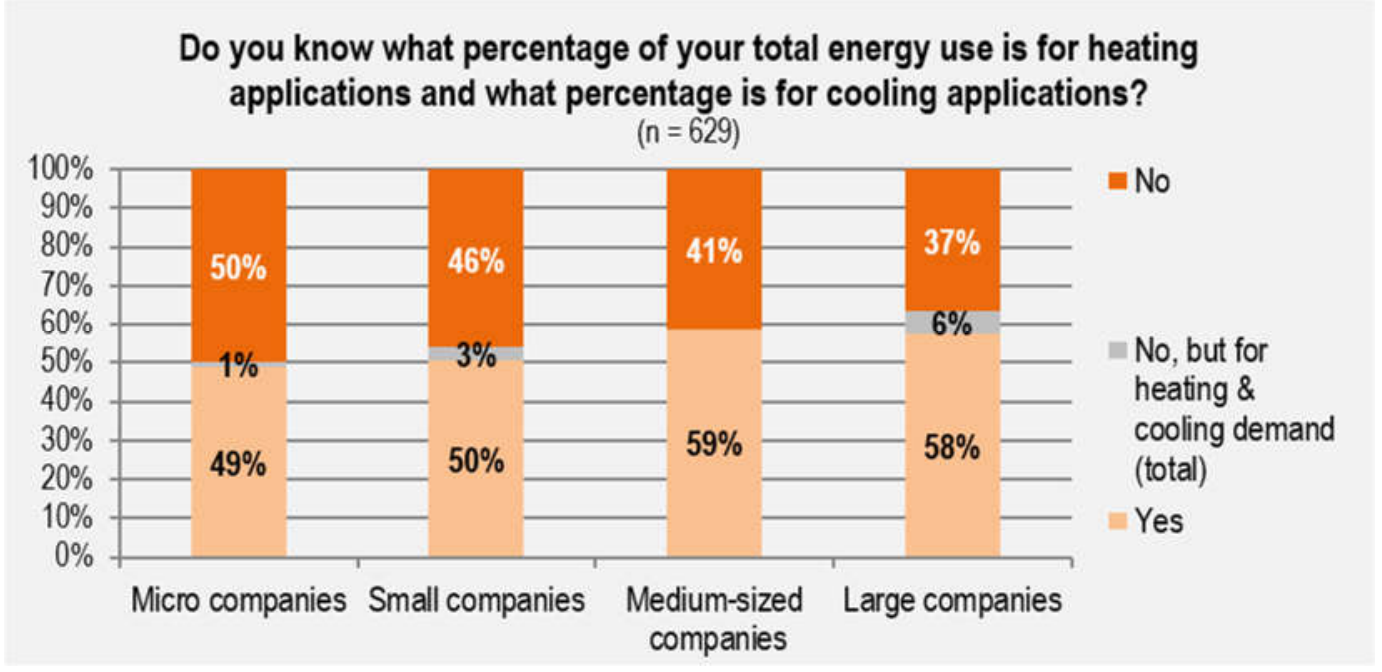

Figure 8: Companies' knowledge of share of energy used for heating and cooling [33] 


\section{Do you use the following waste heat recovery technologies?}

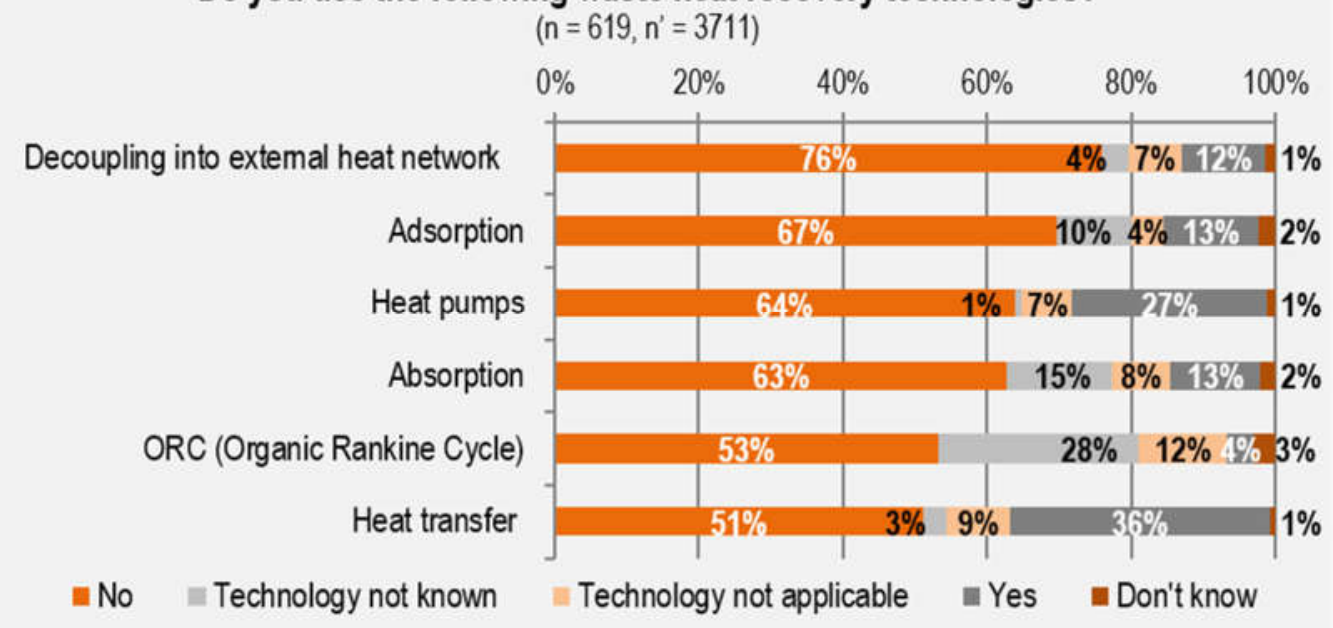

How many of these waste heat recovery technologies

do you use?

$(n=652)$

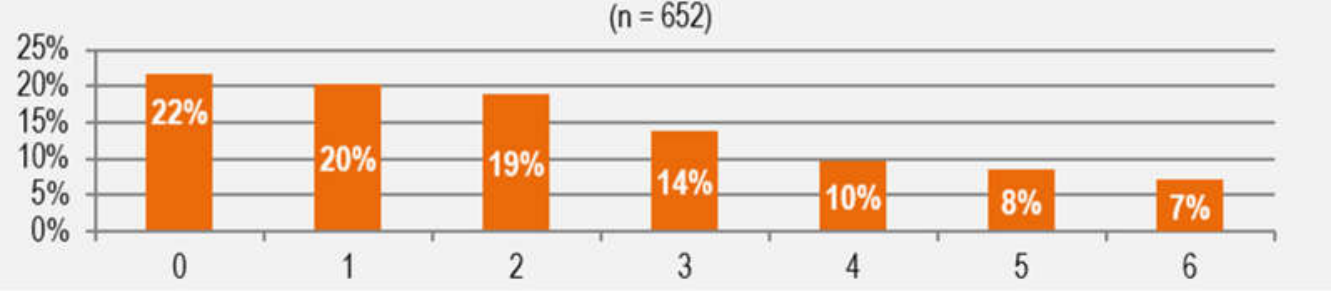

Figure 9: Waste heat recovery technologies used [33]

Acquiring a fair understanding of the status quo, the base, the road to neutrality is built on, is the foundation of all further steps and hence the seventh success criterion.

With the answers to these seven foundational questions, spanning across economic, technical, strategic, principled, and geo-spatial dimensions, it is then feasible for stakeholders to derive both general and specific ways forward.

\subsection{General}

In essence, it now matters- building on the answers to the seven foundational questions - to determine the proportion to which the goal is to be achieved through measures that can be implemented locally and measures that are to be implemented externally or by others.

As described by Buettner et al. [29] internal measures can include:

- Reduction of energy consumption (and of the connected load) through energy efficiency measures, including utilising waste energy and passive resources such as passive ventilation or solar gains.

- Reduction of process-related or process-induced emissions, for instance by substituting coke by green hydrogen in steel production or emissions released by the process itself.

- Self-generation of renewable energies and their storage, for instance solar-, wind-, hydro- or geothermal energy, including means of flexibilising the energy demand.

External measures are all other measures, such as:

- Acquisition of renewable energy (e.g., electricity, hydrogen, biomass, biogas, district heating)

- Procurement of (intermediate) products, raw materials, services, and mobility that have a net-zero emission footprint - either directly acquired on the market or via requirements set for suppliers. 
- Offsetting emissions through projects (e.g., afforestation or efficiency-replacement programs through one's own products - comparable to a self-initiated scrappage scheme)

- Offsetting through purchase of certificates.

- Acceptance of the payment of emission charges (in this case 'net-zero' is out of reach in most scenarios).

Carbon capture and storage or utilisation (CCU/CCS/CCUS) is an additional measure that however does not avoid the emergence of emissions but prevents them from being emitted into the atmosphere. While emissions are captured locally (internal measure) their further treatment can take place locally, but also elsewhere (external measure) [38].

To determine the sequence of measures and the split between local and external measures, both the prioritisation procedures and the scoping outcomes are instrumental as the potential effect of individual measures, investment cost, complexity, payback time and other key performance indicators will differ and need to be weighted.

It needs to be stated, that the split will change over time and with progressing implementation. Bosch for instance announced in May 2019 that it would reach carbon neutrality by 2020 [46]. This was only feasible by launching activities in all areas. As local measures could not all be implemented within that short period, the coverage gap was addressed through offsetting via climate protection projects and acquisition of green energy. With progressing implementation of local measures these external measures can be melt down to a degree until the optimal constellation for net-zero carbon emission is reached. In the meantime, Bosch has changed to the political target dimension of the European Union, climate neutrality and clarified that succeeding in their original area of observation (Scope 1+2), they are now working on Scope 3 [66].

Unless addressed when responding to the seven foundational questions, it is essential to take the decision whether the tool of compensation through projects or certificates is within one's toolkit. Offsetting does allow reaching net-zero in an expedited manner at the additional cost of the certificates/for the projects - literally buying time until emission saving measures implemented locally take an effect. Accepting emission costs until these can be avoided 'naturally' is the alternative. To the author's experience several companies rule out compensation as instrument of their decarbonisation toolkit, as they consider it either cheating as it does not help them to reach actual zero emissions or are risk-averse wishing to avoid the repercussions if such projects are found to be dubious or faulty, or simply want to work towards zero 'naturally' [67-69].

\subsection{Specific}

Beyond the general types of measures described in the previous sub-chapter, there are further interventions, very specific to the situation of a stakeholder and their status quo, that present an opportunity take a technology leap on the way to shape a net-zero business model. This is to replace machinery and equipment with innovative cutting-edge ones that also allow to capitalise on the opportunities presented by automation, digitalisation and machine learning. This can for instance be control systems that adjust source of energy, storage and a range of energy flexibility means by the current availability and price of clean energy, including virtual storage [70]. Another example are factory operation systems that report machine data to a central dashboard in a plug-n-play manner, similar to the interoperability of "Internet of Things" (IoT) devices in more recent smart home systems or computer operating systems adjusting to different form factors via drivers built around a core operating system [71].

In addition to this, Sustainability Key Performance Indicators (KPIs) can be defined based on the decisions taken until this point to allow strategic management to monitor the progress on and effectively pursue the road to net-zero, but also as basis for sustainability reporting [72-73].

\subsection{Economic viability}


Buettner and Wang (2022) [38] point out that in context of decarbonisation it is necessary to reconsider traditional economic viability calculations to assess the economic performance of technically feasible measures. This is as the traditional model does neither account for increasing energy costs, nor for the increasing costs of inaction in the format of emission pricing (EU ETS for instance has risen by over $50 \%$ between 01 November 2021 and 01 February 2022 [59]). Further, a short payback time is often a key decision criterion due to various reasons including business cycles, useful life of machinery etc. In context of decarbonisation, it however makes sense to look for the best constellation for the respective milestone or target year.

To apply this, all types of measures remaining up to this point are to be assessed based on their economic merits including emission costs avoided, and then weighted and scored as defined by the stakeholder. Simplified, the resulting ranking order constitutes the ideal configuration at that very point of time. 'Simplified' as some measures might depend on each other, are not compatible or only unleash their highest efficiency if applied in a bundle.

\subsection{Digitalisation}

As energy prices and emission costs change over time, the ideal configuration changes over time, too. To keep one's ideal decarbonisation strategy up to date with energy and emission price developments it makes sense to make the ranking table of measures dynamically respond to such changes. This is of particular relevance as these cost-changes can have a significant impact on the ranking order of potential measures in a multiple year timeframe. As described by Buettner and Wang [38], building on energy and emission cost schedules and forecasts it is then feasible to optimise the mix of measures based on specific milestone or target years, respectively a combination of these.

Combining all of the factors discussed in this chapter result in a focus-, situation-, priority- and specificity-driven approach, a very individual puzzle that changes its configuration over time.

\section{Conclusion and Discussion}

Within this article, the author illustrated how the methods applied lead to an understanding how everything is connected and provides a step-by-step overview on seven foundational aspects that require attention and aide decision makers in shaping a successful and effective decarbonisation strategy.

Even though the general approach towards what needs to be done may be similar to approaches applied by others, this roadmap to neutrality differs by (a) taking the perspective of an executive decision maker on the demand-side and (b) by going a level deeper, where most other approaches indicate what needs to be done, either in general from a system or country level [24-25], or on a micro level (i.e., technical optimisation options and procedures) [21-22,37]. In addition, where existing approaches outline technical roadmaps [37] or indicate what has to be done but not always how [26-28,74] and remain short of putting it in context, the approach presented explained the underlying strategic aspects that need to be taken on beforehand. One to be aware of the implications and two, to be able to do so in the best manner and interest of the company.

Determining one's ideal decarbonisation strategy, associated decarbonisation roadmap and range of concrete measures essentially comes down to considering one's situation, priorities \& motivations, and focus. With these - addressed by the seven success criteria, one's specific puzzle of measures falls into place.

It however remains to be underlined that the road to net-zero does not end with meeting the (milestone-)targets set within time. Like reaching one's ideal weight, it is one challenge to reach it, and another one to keep it. The ideal mixture of measures to maintain it is likely to change with time, situation, and environment. 
Applying means of digitalisation and an adjusted form of economic viability assessment as described will ease the challenge of keeping the decarbonisation strategy and associated mix of measures ideal and in line with current prices, availabilities, changing environments and policies over time.

Data of the Energy Efficiency Index of German Industry illustrated that a significant proportion of manufacturers participating in the survey already is on a good path, however the remaining companies need to be picked up and lots of work remains to be done across all areas looked at to successfully transition to a net-zero economy and to keep it net-zero.

Even though most of the evidence was gathered from German manufacturers and reflects the situation in Germany, it can be considered that the seven foundational questions are likely to remain valid irrespective of geography or culture. It is however likely, that they are answered differently. Therefore, the currently ongoing data collection via the Energy Efficiency Barometer of Industry and with bodies, stakeholders and companies in other geographies is of particular interest. Whether the seven questions can be also applied to areas outside industry remains to be assessed by further analysis.

Supplementary Materials: No supplementary material is provided. The data presented in this study is available on request from the corresponding author. The data is not publicly available due to privacy issues.

Funding: The article processing charge was funded by the Deutsche Forschungsgemeinschaft (DFG) in the funding programme Open Access Publishing.

\section{Institutional Review Board Statement: Not applicable.}

Informed Consent Statement: Informed consent was obtained from all subjects involved in the study.

Data Availability Statement: The data presented in this study are available on request from the corresponding author. The data are not publicly available due to privacy issues.

Acknowledgments: In this section, you can acknowledge any support given which is not covered by the author contribution or funding sections. This may include administrative and technical support, or donations in kind (e.g., materials used for experiments).

The underlying research in form of the Energy Efficiency Index of German Industry (EEI, \#EEIndex) would not have been possible without the continuous support of the Karl-Schlecht-Foundation and the Heinz und Heide Dürr Foundation, as well as the companies participating and the network of partners of the EEI, as well as those reviewing and supporting in progress of developing this paper and the EEI data collection process, notably Samuel Wörz, Ole Pfister, Anabel Reichle and Frederick Vierhub-Lorenz, the decarbonisation team and the team of student researchers.

In Germany, evidence is usually collected each April/May and October/November (www.eep.unistuttgart.de/eei); the \#EEBarometer runs all year round in 9 further languages across 88 countries (www.eep.uni-stuttgart.de/eeei). Summarised results and recordings of briefings on the results can also be found there.

All conclusions, errors or oversights are solely the responsibility of the author.

Conflicts of Interest: The author declares no conflict of interest. The funders had no role in the design of the study; in the collection, analyses, or interpretation of data; in the writing of the manuscript; or in the decision to publish the results.

\section{References}

1. McClean, D. Earth Day: 2020 saw a major rise in floods and storms. UNDRR. 21 April 2021. Available online: https://www.undrr.org/news/earth-day-2020-saw-major-rise-floods-and-storms (accessed on 29 December 2021).

2. Renouf, J.S. Making sense of climate change-the lived experience of experts. Climatic Change 2021, 164, 14, doi: https://doi.org/10.1007/s10584-021-02986-5.

3. Ripple, W. J.; Wolf, C.; Galetti, M.; Newsome, T.M.; Green, T.L.; Alamgir, M.; Crist, E.; Mahmoud, M.I.; Laurance, W.F. The Role of Scientists' Warning in Shifting Policy from Growth to Conservation Economy. BioScience 2018, 68, 239-240, doi: https://doi.org/10.1093/biosci/biy009.

4. Masson-Delmotte, V.; Zhai, P.; Pörtner, H.O.; Roberts, D.; Skea, J.; Shukla, P.R.; Pirani, A.; Moufouma-Okia, W.; Péan, C.; Pidcock, R.; Connors, S.; Matthews, J.B.R.; Chen, Y.; Zhou, X.; Gomis, M.I.; Lonnoy, E. An IPCC Special Report on the impacts of 
global warmin of $1,5^{\circ} \mathrm{C}$ above pre-industrial levels and related global greenhouse gas emission pathways, in the context of strengthening the global response to the threat of climate change, sustainable development, and efforts to eradicate proverty; IPCC, Ed.; 2019. Available online: https://www.ipcc.ch/site/assets/uploads/sites/2/2019/06/SR15_Full_Report_High_Res.pdf (accessed on 31 January 2022).

5. Masson-Delmote, V.; Zhai, P.; Piani, A.; Connors, S. L.; Péan, C.; Berger, S.; Caud, N.; Chen, Y.; Goldfarb, L.; Gomis, M.I.; Huan, M.; Leitzell, K.; Lonnoy, E.; Matthews, J.B.R.; Maycock, T.K.; Waterfield, T.; Yelekci, O.; Yu, R.; Zhou, B. Climate Change 2021 The Physicyl Science Basis - Summary for Policymaker.; IPCC, 2021. Available online: https://www.ipcc.ch/report/ar6/wg1/downloads/report/IPCC_AR6_WGI_SPM_final.pdf (accessed on 31 January 2022).

6. United Nations. Paris Agreement. 2015. Available online: https://unfccc.int/sites/default/files/english_paris_agreement.pdf (accessed on 28 December 2021).

7. IEA. World Energy Outlook 2021. 2021. Available online: https://iea.blob.core.windows.net/assets/4ed140c1-c3f3-4fd9-acae789a4e14a23c/WorldEnergyOutlook2021.pdf (accessed on 28 December 2021).

8. Jugel, C.; Albicker, M.; Bamberg, C.; Battaglia, M.; Brunken, E.; Bründlinger, T.; Dorfinger, P.; Döring, A.; Friese, J.; Gründing, D.; Hader, P.; Horneber, D.; Jankowska, K.; Kuhlman, A.; May, H.; Meidel, E.; Mennel, T.; Nieswand, M.; Richard, P.; Robers, M.; Schenk, A. -K.; Schmelcher, S.; Seidl, H.; Siegemund, S.; Stolte, C.; Strippchen, L.; Weber, G.; Willers, A.; Willke, J. denaLeitstudie Aufbruch Klimaneutralität.; Deutsche Energie-Agentur GmbH, 2021. Available online: https://www.dena.de/fileadmin/dena/Publikationen/PDFs/2021/Abschlussbericht_dena-

Leitstudie_Aufbruch_Klimaneutralitaet.pdf (accessed on 28 December 2021).

9. Climate Action Tracker. CAT net zero target evaluations. 2021. Available online: https://climateactiontracker.org/global/cat-netzero-target-evaluations/ (accessed on 31 December 2021).

10. Net Zero Climate. What is Net Zero?. Available online: https://netzeroclimate.org/what-is-net-zero/ (accessed on 31 December 2021).

11. Net Zero Tracker. Net Zero Tracker Beta. 2021. Available online: https://zerotracker.net/ (accessed on 31 December 2021).

12. Lamb, W.F.; Wiedmann, T.; Pongratz, J.; Andrew, R.; Crippa, M.; Olivier, J.G.J.; Wiedenhofer, D.; Mattioli, G.; Khourdajie, A.A.; House, J.; et al. A review of trends and drivers of greenhouse gas emissions by sector from 1990 to 2018. Environmental Research Letters 2021, 16, 073005, doi: https://doi.org/10.1088/1748-9326/abee4e.

13. IEA. Global Energy Review: CO2 Emissions in 2020. 02 March 2021. Available online: https://www.iea.org/articles/globalenergy-review-co2-emissions-in-2020 (accessed on 28 December 2021).

14. Kim, Y.J.; Brown, M. Impact of domestic energy-efficiency policies on foreign innovation: The case of lighting technologies. Energy Policy 2019, 128, 539-552, doi: https://doi.org/10.1016/j.enpol.2019.01.032.

15. Houde, S.; Spurlock, C.A. Minimum Energy Efficiency Standards for Appliances. Old and New Economic Rationales. Economics of Energy E Environmental Policy 2016, 5, 65-84. Available online: https://www.jstor.org/stable/26189506 (accessed on 28 December 2021).

16. Umweltbundesamt. Energieverbrauch 2020 nach Sektoren und Energieträgern. 2021. Available online: https://www.umweltbundesamt.de/bild/endenergieverbrauch-2020-nach-sektoren (accessed on 10 December 2021).

17. Umweltbundesamt. Energiebedingte Treibhausgas-Emissionen 1990-2019. 2021. Available online: https://www.umweltbundesamt.de/sites/default/files/styles/800w400h/public/medien/384/bilder/2_abb_energiebed-thgemi_2021-06-02.png (accessed on 10 December 2021).

18. Umweltbundesamt. Entwicklung der Treibhausgasemissionen in Deutschland 2010-2019. 2021. Available online: https://www.umweltbundesamt.de/sites/default/files/medien/421/bilder/1_entwicklung_der_treibhausgasemissionen_in_deut schland_0.jpg (accessed on 10 December 2021).

19. IEA. Global CO2 emissions by sector, 2019. 10 August 2021. Available online: https://www.iea.org/data-andstatistics/charts/global-co2-emissions-by-sector-2019 (accessed on 31 January 2022).

20. IEA. Key World Energy Statistics 2021. 2021. Available online: https://www.iea.org/reports/key-world-energy-statistics-2021 (accessed on 31 January 2022).

21. Nurdiawati, A.; Urban, F. Towards Deep Decarbonisation of Energy-Intensive Industries: A Review of Current Status, Technologies and Policies. Energies 2021, 14, 2408. doi: https://doi.org/10.3390/en14092408.

22. Bauer, F. Assessing the feasibility of archetypal transition pathways towards carbon neutrality - A comparative analysis of European industries. Elsevier 2022, 177, 106015, doi: https://doi.org/10.1016/j.resconrec.2021.106015.

23. Bataille, C.; Åhman, M.; Neuhoff, K.; Nilsson, L.J.; Fischedick, M.; Lechtenböhmer, S.; Solano-Rodriquez, B.; Denis-Ryan, A.; Stiebert, S.; Waisman, H.; et al. A review of technology and policy deep decarbonization pathway options for making energyintensive industry production consistent with the Paris Agreement. Journal of Cleaner Production 2018, 187, 960-973, doi: https://doi.org/10.1016/j.jclepro.2018.03.107.

24. Rissman, J.; Bataille, C.; Masanet, E.; Aden, N.; Morrow, W.R.; Zhou, N.; Elliott, N.; Dell, R.; Heeren, N.; Huckestein, B.; et al. Technologies and policies to decarbonize global industry: Review and assessment of mitigation drivers through 2070. Applied Energy 2020, 266, 114848, doi: https://doi.org/10.1016/j.apenergy.2020.114848.

25. Johnson, O. W.; Mete, G.; Sanchez, F.; Shawoo, Z.; Talebian, S. Towards Climate-Neutral Heavy Industry: An Analysis of Industry Transition Roadmaps. Applied science 2021. 11, 5375, doi: https://doi.org/10.3390/app11125375.

26. South Pole. Become Climate Neutral. 2021. Available online: https://www.southpole.com/sustainability-solutions/becomeclimate-neutral (accessed on 31 December 2021). 
27. Climate Neutral. How it works. 2021. Available online: https://www.climateneutral.org/how-it-works (accessed on 31 December 2021).

28. Fashion Cloud. So wird dein Unternehmen klimaneutral. 2021. Available online: https://fashion.cloud/de/so-wird-deinunternehmen-klimaneutral/ (accessed on 31 December 2021).

29. Buettner, S.M.; Schneider, C.; König, W.; Mac Nulty, H.; Piccolroaz, C.; Sauer, A. How do German manufacturers react to the increasing societal pressure for decarbonisation? Applied Sciences 2022, 12, 543, doi: https://doi.org/10.3390/app12020543.

30. EEP. Der Energieeffizienz-Index der Deutschen Industrie. Umfrageergebnisse 2. Halbjahr 2019; Institut für Energieeffizienz in der Produktion, Universität Stuttgart: Stuttgart, Germany, 2019. Available online: https://www.eep.uni-stuttgart.de/eei/archiv-aeltere-erhebungen/ (accessed on 08 February 2022).

31. EEP. Der Energieeffizienz-Index der Deutschen Industrie. Umfrageergebnisse 1. Halbjahr 2020; Institut für Energieeffizienz in der Produktion, Universität Stuttgart: Stuttgart, Germany, 2020. Available online: https://www.eep.uni-stuttgart.de/eei/archiv-aeltere-erhebungen/ (accessed on 08 February 2022).

32. EEP. Der Energieeffizienz-Index der Deutschen Industrie. Umfrageergebnisse 2. Halbjahr 2020; Institut für Energieeffizienz in der Produktion, Universität Stuttgart: Stuttgart, Germany, 2020. Available online: https://www.eep.uni-stuttgart.de/eei/archiv-aeltere-erhebungen/ (accessed on 08 February 2022).

33. EEP. Der Energieeffizienz-Index der Deutschen Industrie. Umfrageergebnisse 1. Halbjahr 2021; Institut für Energieeffizienz in der Produktion, Universität Stuttgart: Stuttgart, Germany, 2021. Available online: https:/www.eep.uni-stuttgart.de/eei/archiv-aeltere-erhebungen/ (accessed on 08 February 2022).

34. EEP. Der Energieeffizienz-Index der Deutschen Industrie. Umfrageergebnisse 2. Halbjahr 2021; Institut für Energieeffizienz in der Produktion, Universität Stuttgart: Stuttgart, Germany, 2022. Available online: https://www.eep.uni-stuttgart.de/eei/ (accessed on 08 February 2022).

35. Weber, R. Wärmepumpen als Klimaretter? 2021. Available online: https://www.daserste.de/information/wirtschaft-boerse/plusminus/sendung/waermepumpe-bewertung-100.html (accessed on 30 December 2021).

36. Cresko, J.; Shenoy, D.; Liddell, H.P.; Sabouni, R. Quadrennial Technology Review 2015. U.S. Department of Energy. United States of America, 2015: pp. 180-225.

37. Buettner, S.M. Framing the Ambition of Carbon Neutrality, UNECE Task Force on Industrial Energy Efficiency. In Group of Experts on Energy Efficiency; GEEE-7/2020/INF.2; United Nations Economic Commission for Europe: Geneva, Switzerland, 2020. Available online: https://www.unece.org/fileadmin/DAM/energy/se/pdfs/geee/geee7_Sept2020/GEEE-7.2020.INF.2_final_v.2.pdf (accessed on 08 February 2022).

38. Buettner, S.M.; Wang, D. A pathway to reducing greenhouse gas footprint in manufacturing: Determinants for an economic assessment of industrial decarbonisation measures. 2022, Unpublished.

39. DPA. Japans neuer Ministerpräsident peilt Klimaneutralität bis 2050 an. Handelsblatt. 26 October 2020. Available online: https://www.handelsblatt.com/politik/international/energiewende-japans-neuer-ministerpraesident-peilt-klimaneutralitaetbis-2050-an/26307902.html (accessed on 30 December 2021).

40. Dooley, B.; Inoue, M.; Hida, H. Japan's new Leader Sets Ambitious Goal of Carbon Neutrality by 2050. The New York Times. 30 November 2020. Available online: https://www.nytimes.com/2020/10/26/business/japan-carbon-neutral.html (accessed on 30 December 2021).

41. Watkins, M. D. Demystifying Strategy: The What, Who, How, and Why. Harvard Business Review. 10 September 2007. Available online: https://hbr.org/2007/09/demystifying-strategy-the-what\#: :text=A\%20good\%20strategy\%20provides\%20a,prioritize)\%20to\%20achieve\%20desired\%20goals. (accessed on 04 February 2022).

42. Groups of Experts on Cleaner Electricity Systems. Framework for attaining carbon neutrality in the United Nations Economic Commission for Europe (ECE) region by 2050. ECE/ENERGY/GE.5/2020/8 Rev.1. United Nations Economic and Social Council. 25 October 2020. Available online: https://unece.org/fileadmin/DAM/energy/se/pdfs/CES/ge16_2020/ECE_ENERGY_GE.5_2020_8_rev1.pdf (accessed on 07 February 2022).

43. G2G. G2G Talk: An interview with Olga Algayerova. How is the UN Economic Commission for Europe (UNECE) working with countries to attain Carbon Neutrality in the ECE Region? 2021. Available online: https://www.c2g2.net/c2gtalk-olga-algayerova/ (accessed on 31 December 2021).

44. U.S. Department of State. United States, European Union, and Partners Formally Launch Global Mathane Pledge to Keep 1,5C Within Reach. 2021. Available online: https://www.state.gov/united-states-european-union-and-partners-formally-launchglobal-methane-pledge-to-keep-1-5c-within-reach/ (accessed on 30 December 2021).

45. Müller, B. So will RWE bis 2040 klimaneutral werden. Süddeutsche Zeitung. 01 October 2019. Available online: https://www.sueddeutsche.de/wirtschaft/rwe-klimaneutral-2040-1.4622120 (accessed on 04 February 2022).

46. Mazzei, A. Climate action: Bosch to be carbon neutral worldwide by 2020. Bosch. 09 May 2019. Available online: https://www.bosch-presse.de/pressportal/de/en/climate-action-bosch-to-be-carbon-neutral-world-wide-by-2020-188800.html (accessed on 04 February 2022).

47. Jeudy-Hugo, S.; Lo Re, L.; Falduto, C. Understanding Countries Net-Zero Emissions Targets. OECD. 22 October 2021. Available online: https://www.oecd.org/officialdocuments/publicdisplaydocumentpdf/?cote=COM/ENV/EPOC/IEA/SLT(2021)3\&docLanguage=En (accessed on 07 February 2022).

48. Bundesverfassungsgericht. Constitutional complaints against the Federal Climate Change Act partially successful. 29 April 2021. Available online: https://www.bundesverfassungsgericht.de/SharedDocs/Pressemitteilungen/EN/2021/bvg21-031.html (accessed on 31 December 2021). 
49. Spier, J. 'The "Strongest" Climate Ruling Yet': The Dutch Supreme Court's Urgenda Judgment. Netherlands International Law Review 2020, 67, 319-391, doi: https://doi.org/10.1007/s40802-020-00172-5.

50. Evans, S.; Gabbatiss, J.; McSweeney, R.; Chandrasekhar, A.; Tandon, A.; Viglione, G.; Hausfather, Z.; You, X.; Goodman, J.; Hayes, S. COP26: Key outcomers agreed at the UN climate talks in Glasgow. Carbon Brief Staff. 15 November 2021. Available online: https://www.carbonbrief.org/cop26-key-outcomes-agreed-at-the-un-climate-talks-in-glasgow (accessed on 31 December 2021).

51. Buettner, S.M.; Döpp, J.; König, W.; Strauch, L.; Increasing the voltage - sequencing decarbonisation with green power \& efficiency. 2022, Unpublished.

52. Greenhouse Gas Protocol. FAQ. World Resources Institute. Available online: https://ghgprotocol.org/sites/default/files/standards_supporting/FAQ.pdf (accessed on 30 December 2021).

53. Rajan, A. The daunting task of decarbonising investment portfolios. Financial Times. 24 February 2020. Available online: https://www.ft.com/content/ecdf1231-93d6-4819-a32a-a49a7a25fcea (accessed on 31 January 2022).

54. European Environment Agency. CO2 performance of new passenger cars in Europe. 18 November 2021. Available online: https://www.eea.europa.eu/ims/co2-performance-of-new-passenger (accessed on 30 December 2021).

55. Volkswagen. Volkswagen way to Zero. 2021. Available online: https://www.volkswagen.de/de/marke-und-erlebnis/waytozero.html (accessed on 31 December 2021).

56. World Economic Forum. Net-Zero Challenge: The Supply chain opportunity. January 2021. Available online: https://www3.weforum.org/docs/WEF_Net_Zero_Challenge_The_Supply_Chain_Opportunity_2021.pdf (accessed on 06 February 2022).

57. Haupt, C. BASF ermittelt CO2-Fußabdruck aller Verkausprodukte. Wirtschaftspresse. 28 July 2020. Available online: https://www.basf.com/global/de/media/news-releases/2020/07/p-20-260.html (accessed on 31 December 2021).

58. Buettner, S.M.; König, W. Looking behind decarbonisation-what pressure points trigger action? In Proceedings of the eceee Summer Study, 7-11 June 2021, digital, 2021; pp. 345-354.

59. Ember. Daily Carbon Prices. 2022. Available online: https://ember-climate.org/data/carbon-price-viewer/ (accessed on 07 February 2022).

60. Stratmann, K. Erste Unternehmen kapitulieren vor hohen Gas- und Strompreisen - Was die Politik nun tun will. Handelsblatt. 01 January 2022. Available online: https:/www.handelsblatt.com/politik/deutschland/strom-und-gas-erste-unternehmen-kapitulieren-vor-hohen-gas-und-strompreisen-was-die-politik-nun-tun-will/27935982.html (accessed on 31 January 2022).

61. Flauger, J. Kersting, S. Der Strompreis-Schock: Industrie zahlt so viel wie seit einem Jahrzehnt nicht mehr. Handelsblatt. 29 June 2021. Available online: https://www.handelsblatt.com/unternehmen/energie/energiewirtschaft-der-strompreis-schock-industrie-zahlt-so-viel-wie-seit-einem-jahrzehnt-nicht-mehr/27360246.html (accessed on 31 January 2022).

62. DIHK. DIHK_Umfrage: Unternehmen leiden unter hohen Strom- und Gaspreisen. 22 November 2021. Available online: https://www.dihk.de/de/themen-und-positionen/wirtschaftspolitik/energie/dihk-umfrage-unternehmen-leiden-unter-hohenstrom-und-gaspreisen-61652 (accessed on 31 January 2022).

63. Rieger, J. Insolvent trotz guter Auftragslage. SWR. 14 January 2022. Available online: https://www.tagesschau.de/wirtschaft/unternehmen/gaspreise-insolvenzen-unternehmen-101.html (accessed on 31 January 2022).

64. Buettner, S.M.; König, W. Determining the ideal mix - (finding out) what range of measures is best for one's business? In Proceedings of the ACEEE Summer Study, digital, 13-15 July 2021. Available online: https://www.aceee.org/sites/default/files/pdfs/ssi21/panel-2/Buettner.pdf (accessed on 08 February 2022).

65. Aurubis AG. CO2-free heat supply for Hamburg's Hafen City district. Available online: https://www.wire-tradefair.com/cgibin/md_wiretube/lib/pub/tt.cgi?oid=2377518\&lang=2 (accessed on 06 February 2022).

66. Bosch. Unternehmensweiter Umweltschutz: Klimaneutralität seit 2020. 2022. Available online: https://www.bosch.com/de/nachhaltigkeit/umwelt/ (accessed on 31. January 2022).

67. Economento. Greenpeace wirft VW fehlende CO2-Kompensation bei ID. - Elektroautos vor. 30 September 2020. Available online: https://ecomento.de/2020/09/30/greenpeace-wirft-vw-fehlende-co2-kompensation-bei-elektroautos-vor/ (accessed on 31 January 2022).

68. Greenfield, P. Carbon offsets used by major airlines based on flawed system, warn experts. The Guardian. 4 May 2021. Available online: https://www.theguardian.com/environment/2021/may/04/carbon-offsets-used-by-major-airlines-based-on-flawed-system-warn-experts (accessed on 31 January 2022).

69. AL Ghussain, A. The biggest problem with carbon offsetting is that it doesn't really work. Greenpeace. 26 May 2020. Available online: https://www.greenpeace.org.uk/news/the-biggest-problem-with-carbon-offsetting-is-that-it-doesnt-really-work/ (accessed on 31 January 2022).

70. Federal Ministry of Education and Research. How the Kopernicus project SynErgie helps industry match its electricity demand to the supply. Available online: https://www.kopernikus-projekte.de/en/projects/synergie (accessed on 31 January 2022).

71. FABOS. FABOS-open, distributed, real-time capable and secure operation system for production. 2022. Available online: https://www.fab-os.org/en/ (accessed on 28 January 2022).

72. Wang, D. KPIs in CSR reporting as a vehicle for climate neutrality. In European Council for an Energy Efficient Economy ECEEE Summer Study, digital, 7-11 June 2021. Presentation.

73. Hristov, I.; Chirico, A. The Role of Sustainability Key Performance Indicators (KPI's) in Implementing Sustainable Strategies. Sustainability 2019, 11, 5742, doi: https://doi.org/10.3390/su11205742. 
74. The Economist Applied. How do you make your company carbon-neutral?. 10 November 2020. Available online: https://applied.economist.com/articles/how-do-you-go-carbon-neutral (accessed on 28 January 2022). 